\title{
EFEITO DE DIFERENTES TEMPERATURAS DE APLICAÇÃO OU NÃO DE ETILENO EXÓGENO SOBRE A QUALIDADE DA MANGA 'TOMMY ATKINS'
}

\author{
JUAN SAAVEDRA DEL AGUILA², EDWIN MOISÉS MARCOS ORTEGA ${ }^{3}$, \\ LÍLIA SICHMANN HEIFFIG-DEL AGUILA ${ }^{4}$, RICARDO ALFREDO KLUGE ${ }^{5}$
}

RESUMO - A manga é uma espécie originária da Índia, estando atualmente distribuída por praticamente todas as regiões tropicais do mundo, sendo cultivada comercialmente também em algumas regiões de clima subtropical. $\mathrm{O}$ interesse pela cultura deve-se à excelência de seus frutos que, além de apresentar sabor exótico, são ricos em vitaminas e sais minerais, sendo uma das frutas mais ricas em vitamina A. O objetivo do presente trabalho foi estudar o efeito de diferentes temperaturas de aplicação de etileno exógeno sobre a qualidade de manga 'Tommy Atkins'. Os tratamentos foram: $\mathrm{T} 1=$ frutos armazenados sob condições não controladas $\left(24^{\circ} \mathrm{C} \pm 5^{\circ} \mathrm{C}\right.$ e $\left.65 \% \mathrm{UR}\right)$ e não aplicação de etileno (tratamento-controle); $\mathrm{T} 2=$ frutos sob condições não controladas, com $25 \mathrm{ppm}$ de etileno, por $2 \operatorname{dias}\left(24^{\circ} \mathrm{C} \pm 5^{\circ} \mathrm{C}\right.$ e $\left.65 \% \mathrm{UR}\right)$; T3= frutos sob temperatura de $16^{\circ} \mathrm{C} \pm 1^{\circ} \mathrm{C}$ e $90 \%$ UR, com $25 \mathrm{ppm}$ de etileno, por 2 dias; T4= frutos sob temperatura de $18^{\circ} \mathrm{C} \pm 1{ }^{\circ} \mathrm{C}$ e $90 \%$ $\mathrm{UR}$, com $25 \mathrm{ppm}$ de etileno, por 2 dias; T5 = frutos sob temperatura de $20^{\circ} \mathrm{C} \pm 1^{\circ} \mathrm{C}$ e $90 \% \mathrm{UR}$, com $25 \mathrm{ppm}$ de etileno, por 2 dias; $\mathrm{T} 6=$ frutos sob temperatura de $22^{\circ} \mathrm{C} \pm 1^{\circ} \mathrm{C}$ e $90 \% \mathrm{UR}$, com $25 \mathrm{ppm}$ de etileno, por 2 dias, e T7 $=$ frutos sob temperatura de $24^{\circ} \mathrm{C} \pm 1^{\circ} \mathrm{C}$ e $90 \%$ UR, com $25 \mathrm{ppm}$ de etileno, por 2 dias. Após os tratamentos, os frutos foram armazenados a $20^{\circ} \mathrm{C} \pm 1{ }^{\circ} \mathrm{C}$ e $90 \% \mathrm{UR}$ (T3 a T7) e a condições ambientais não controladas $\left(24^{\circ} \mathrm{C} \pm 5^{\circ} \mathrm{C}\right.$ e $65 \%$ UR), nos tratamentos T1 e T2, por 14 dias. Avaliaram-se os frutos na colheita (caracterização), após os tratamentos no dia 0 , no $7^{\circ}$ e no $14^{\circ}$ dias. Determinaram-se: sólidos solúveis totais, acidez titulável, índice de coloração do pericarpo e da polpa, firmeza manual do fruto e podridões. Conclui-se que a temperatura de $20^{\circ} \mathrm{C}$ é a sugerida para a aplicação de etileno exógeno para o amadurecimento uniforme de manga ‘Tommy Atkins'.

Termos para indexação: Mangifera indica L.; fitohormônio; aparência.

\section{EFFECT OF DIFFERENT TEMPERATURES OF EXOGENOUS ETHYLENE ON FRUIT PRODUTIVITY OF 'TOMMY ATKINS' MANGO}

\begin{abstract}
Mango is a species from India, currently spread over nearly all tropical regions of the world, being grown commercially also in some regions of subtropical climate. The interest in the crop is due to the excellence of the fruit, which, besides presenting exotic flavor, is rich in vitamins and minerals, being one of the richest fruits in vitamin A. The objective of this work was to study the effect of different temperatures of ethylene application on the mango 'Tommy Atkins quality. The treatments were: $\mathrm{T} 1=$ fruits stored under uncontrolled conditions $\left(24^{\circ} \mathrm{C} \pm 5^{\circ} \mathrm{C}\right.$ and $\left.65 \% \mathrm{RH}\right)$ and without ethylene (control), $\mathrm{T} 2=$ fruits under uncontrolled conditions - with $25 \mathrm{ppm}$ ethylene for 2 days $\left(24^{\circ} \mathrm{C} \pm 5^{\circ} \mathrm{C}\right.$ and $\left.65 \% \mathrm{RH}\right), \mathrm{T} 3=$ fruits at a temperature of $16^{\circ} \mathrm{C} \pm 1{ }^{\circ} \mathrm{C}$ and $90 \% \mathrm{RH}$, with $25 \mathrm{ppm}$ ethylene for 2 days, $\mathrm{T} 4=$ fruits at a temperature of $18^{\circ} \mathrm{C} \pm 1{ }^{\circ} \mathrm{C}$ and $90 \% \mathrm{RH}$, with $25 \mathrm{ppm}$ ethylene for 2 days, $\mathrm{T} 5$ = fruits at a temperature of $20^{\circ} \mathrm{C} \pm 1^{\circ} \mathrm{C}$ and $90 \% \mathrm{RH}$, with $25 \mathrm{ppm}$ ethylene for 2 days, $\mathrm{T} 6=$ fruits at a temperature of $22^{\circ} \mathrm{C} \pm 1{ }^{\circ} \mathrm{C}$ and $90 \% \mathrm{RH}$, with $25 \mathrm{ppm}$ ethylene for 2 days and $\mathrm{T} 7=$ fruits at a temperature of $24^{\circ} \mathrm{C} \pm 1{ }^{\circ} \mathrm{C}$ and $90 \% \mathrm{RH}$, with 25 ppm ethylene for 2 days. After treatment, fruits were stored at $20^{\circ} \mathrm{C} \pm 1{ }^{\circ} \mathrm{C}$ and $90 \% \mathrm{RH}(\mathrm{T} 3$ and T7) and uncontrolled environmental conditions $\left(24^{\circ} \mathrm{C} \pm 5^{\circ} \mathrm{C}\right.$ and $\left.65 \% \mathrm{RH}\right)$ in $\mathrm{T} 1$ and $\mathrm{T} 2$, for 14 days. Fruits were characterized at harvest and after treatment, $0,7^{\text {th }}$ and $14^{\text {th }}$ days. Soluble solids, acidity, skin colour and pulp colour, manual firmness of fruits and rot. It was concluded that the temperature of $20^{\circ} \mathrm{C}$, can be suggested for the application of exogenous ethylene for uniform ripening on mango 'Tommy Atkins'.
\end{abstract}

Index terms: Mangifera indica L.; phytohormone; appearance.

\footnotetext{
${ }^{1}$ Trabalho Sinfruit 039 - Simpósio Internacional de Fruticultura - Avanços na Fruticultura (17 a 21 Outubro) ${ }^{2}$ Pós-Doutorando do Departamento de Ciências Biológicas, Escola Superior de Agricultura "Luiz de Queiroz" (ESALQ), Universidade de São Paulo (USP), Caixa Postal 09, 13418-900, Piracicaba-SP, Brasil. E-mail: jsaguila@esalq.usp.br ${ }^{3}$ Departamento de Ciência Exatas, ESALQ/USP, Caixa Postal 09, 13418-900, Piracicaba-SP. E-mail: edwin@esalq.usp.br ${ }^{4}$ Pesquisadora da Embrapa Clima Temperado, Caixa Postal 403, 96010-971, Pelotas-RS. E-mail: lilia.sichmann@cpact.embrapa.br 5rakluge@esalq.ups.br
} 


\section{INTRODUÇ̃̃O}

A manga (Mangifera indica L.) é um dos mais importantes frutos tropicais em termos de produção e aceitação pelo consumidor; é uma fonte rica de antioxidantes, como ácido ascórbico, carotenoides e compostos fenólicos (SIMÃO, 1998; GALÁN SAÚCO, 1999; RIBEIRO et al., 2008).

A produção comercial no Brasil está localizada, principalmente, nas regiões Sudeste e Nordeste do País, onde as temperaturas permanecem elevadas praticamente o ano todo. Os principais Estados produtores são: Bahia, São Paulo, Pernambuco, Minas Gerais, Ceará, Rio Grande do Norte e Paraíba, e as principais cultivares utilizadas são: Tommy Atkins, Haden, Keitt, Van Dyke e Rosa (SÃO JOSÉ, 1996; AGRIANUAL, 2008).

A variedade 'Tommy Atkins' foi obtida na década de 1920, em Fort Lauderdale, Estado da Flórida, nos Estados Unidos. A árvore tem uma copa arredondada, densa e apresenta tolerância à antracnose e ao oídio. Os frutos são de tamanho médio a grande, de casca grossa e forma ovaloblonga, de semente pequena (que representa 7 a $8 \%$ em relação à polpa). Quando maduros, adquirem cor avermelhada a purpúrea. A polpa é firme e sucosa, apresentando certa quantidade de fibra de boa qualidade (COHEN et al., 2001).

$\mathrm{O}$ etileno $\left(\mathrm{C}_{2} \mathrm{H}_{4}\right)$ é um fitormônio atuante em fases diversificadas, como crescimento, desenvolvimento e senescência, e, principalmente, no amadurecimento de frutas climatéricas. Já está bem estabelecido o envolvimento do etileno na degradação da clorofila, na biossíntese de carotenoides e de antocianinas, porém não está bem esclarecido seu papel regulador. A manga é uma fruta climatérica e pode ser usada a aplicação exógena de etileno para a uniformização do processo de amadurecimento dos frutos.

Durante o processo de amadurecimento da manga, podem-se verificar várias alterações, como na firmeza da polpa, nos teores de açúcares, na coloração da casca e da polpa, na composição e teor de ácidos orgânicos e na perda de massa (FUCHS et al., 1975). Um dos principais problemas encontrados em mangas destinadas ao consumo in natura ou ao processamento é a desuniformidade de amadurecimento dos frutos de um mesmo lote (ROZANE et al., 2004). Dependendo das condições do fruto e das exigências do mercado, a prática do amadurecimento controlado pode ser recomendada. Os frutos colhidos verdes não amadurecem, apresentam polpa branca e murcham. Para um amadurecimento uniforme dos frutos da mangueira, aplica-se etileno, sendo que este ativa as funções metabólicas do fruto e sua ação enzimática, as quais produzem a destruição da clorofila e acentuam cada vez mais os carotenoides. No Brasil, esses gases são comercializados como próprios para o amadurecimento de frutos, sob os nomes "Azetil" e "Etil 5", e são constituídos de uma mistura de 94,5\% de nitrogênio e 5,5\% de etileno.

No Brasil, o consumo de manga está em declínio, e a produção nacional está em queda (AGRIANUAL, 2007), o que pode ser explicado, em parte, pelos frutos sem qualidade, desuniformes quanto à maturação, que geralmente são oferecidos ao consumidor. Outro fator que pode justificar essa queda é a ausência ou, ainda, a limitação do conhecimento sobre os diversos processos metabólicos e fisiológicos associados às técnicas de maturação e conservação pós-colheita da manga.

Na Austrália, utilizam-se 10 ppm de etileno, à temperatura de 18 a $22^{\circ} \mathrm{C}$ e umidade relativa de 85 a $95 \%$, por um período de 1 a 3 dias (MARQUES et al., 2007). No Brasil, o etileno é utilizado na proporção de $2 \%$ do volume da câmara, à temperatura de 22 a $24^{\circ} \mathrm{C}$ e umidade relativa de 85 a $95 \%$, por um período de 3 a 4 dias (BLEINROTH, 1980), segundo Matos (2000), a temperatura recomendada vai de 21 a $24^{\circ} \mathrm{C}$; já, para Medlicott et al. (1986), a faixa de temperatura para o amadurecimento de manga com melhor qualidade varia de 19 a $24^{\circ} \mathrm{C}$.

Apesar das recomendações técnicas do uso de etileno exógeno tanto para o mercado interno quanto para o externo, com o objetivo de obter frutos de qualidade, um grave problema de desuniformidade no amadurecimento dos frutos de um mesmo lote é verificado no comércio interno, assim como naqueles destinados à exportação. Essa desuniformidade de amadurecimento pós-colheita prejudica a aceitação pelo consumidor, mesmo que em alguns casos os frutos apresentem sabor aceitável. Consequentemente, tem-se a perda do valor econômico dos frutos e a não abertura de mais mercados externos para esses frutos, uma vez que os mercados importadores são altamente exigentes quanto à qualidade.

Neste sentido, objetivou-se determinar a melhor temperatura de aplicação de etileno exógeno em frutos da mangueira.

\section{MATERIAL E MÉTODOS}

$\mathrm{O}$ experimento foi desenvolvido no Laboratório de Fisiologia e Bioquímica Pós-Colheita, do Departamento de Ciências Biológicas, da Escola Superior de Agricultura "Luiz de Queiroz" (ESALQ/ USP), no município de Piracicaba-SP, localizado a 
$22^{\circ} 41^{\prime} 30^{\prime \prime}$ de latitude sul, $47^{\circ} 38^{\prime} 30^{\prime \prime}$ de longitude oeste e $546 \mathrm{~m}$ de altitude.

Os frutos da mangueira 'Tommy Atkins' foram colhidos (safra 2009-2010) no estádio verdematuro ("ombros" cheios, firmes e com a casca verde), sendo provenientes de um produtor da região de Taquaritinga-SP (Ogata Cítrus). Imediatamente após a colheita, os frutos da mangueira foram transportados até o Laboratório, onde foram selecionados quanto à firmeza, ausência de danos mecânicos e podridões visíveis.

Para a aplicação do etileno nos diferentes tratamentos, os frutos foram colocados em câmaras hermeticamente fechadas, utilizou-se o "Etil 5" como fonte de etileno, e a concentração almejada foi conferida em cromatógrafo a gás.

Os tratamentos foram os seguintes: $\mathrm{T} 1=$ frutos armazenados sob condições não controladas $\left(24^{\circ} \mathrm{C} \pm 5^{\circ} \mathrm{C}\right.$ e $65 \%$ UR) e não aplicação de etileno (tratamento-controle); T2= frutos armazenados sob condições não controladas, com 25 ppm de etileno, por 2 dias $\left(24^{\circ} \mathrm{C} \pm 5^{\circ} \mathrm{C}\right.$ e $\left.65 \% \mathrm{UR}\right)$; $\mathrm{T} 3=$ frutos armazenados sob temperatura de $16^{\circ} \mathrm{C} \pm 1{ }^{\circ} \mathrm{C}$ e $90 \%$ UR, com 25 ppm de etileno, por 2 dias; T4= frutos armazenados sob temperatura de $18^{\circ} \mathrm{C} \pm 1^{\circ} \mathrm{C}$ e $90 \%$ UR, com 25 ppm de etileno, por 2 dias; T5= frutos armazenados sob temperatura de $20^{\circ} \mathrm{C} \pm 1^{\circ} \mathrm{C}$ e $90 \%$ $\mathrm{UR}$, com 25 ppm de etileno, por 2 dias; $\mathrm{T} 6=$ frutos armazenados sob temperatura de $22^{\circ} \mathrm{C} \pm 1^{\circ} \mathrm{C}$ e $90 \%$ UR, com 25 ppm de etileno, por 2 dias, e T7 = frutos armazenados sob temperatura de $24^{\circ} \mathrm{C} \pm 1^{\circ} \mathrm{C}$ e $90 \%$ UR, com 25 ppm de etileno, por 2 dias.

Após os tratamentos, os frutos foram armazenados a $20^{\circ} \mathrm{C} \pm 1{ }^{\circ} \mathrm{C}$ e $90 \%$ UR (T3 a T7), e a condições ambientais não controladas $\left(24^{\circ} \mathrm{C} \pm 5^{\circ} \mathrm{C} \mathrm{e}\right.$ $65 \%$ UR), nos tratamentos T1 e T2.

Os frutos foram avaliados na chegada ao laboratório (caracterização), imediatamente após a saída dos distintos tratamentos (dia 0 ), no $7^{\circ}$ e no $14^{\circ}$ dia após a finalização dos tratamentos; sendo que os pontos de avaliação visam a avaliar os frutos imediatamente após a aplicação dos tratamentos (dia 0 ), no ponto ótimo de consumo (dia 7) e ao final da vida de prateleira dos mesmos (dia 14).

Determinaram-se: sólidos solúveis totais (SST), após a trituração da amostra em multiprocessador doméstico, uma gota do suco proveniente da trituração foi colocada em um refratômetro digital, os resultados foram expressos em ${ }^{\circ}$ Brix; acidez titulável (AT), foi determinada por titulação com $\mathrm{NaOH} 0,1 \mathrm{~N}$ até $\mathrm{pH} 8,1$, com os resultados expressos em \% de acidez; índice de coloracão do pericarpo, foi utilizada uma escala visual de cores do pericarpo dos frutos, seguindo o método descrito por Braz et al. (2008), com a seguinte equivalência: 1 = totalmente verde; $2=$ mais verde que vermelha; 3 = iguais proporções de verde e vermelha; $4=$ mais vermelha que verde, e 5 = totalmente vermelha; índice de coloração da polpa, foi utilizada uma escala visual de cores da polpa dos frutos, seguindo o método descrito por Braz et al. (2008), com a seguinte equivalência: $1=$ totalmente branca; 2 = branco-amarelada; $3=$ amarela; $4=$ amarelo-alaranjada, e $5=$ totalmente laranja; firmeza manual, foi determinada utilizando um método não destrutivo, mediante o tato com as mãos, seguindo uma escala: $0=$ duro (firme); $1=$ mais ou menos duro; 2 = pouco mole, $3=$ mole, e 4 = muito mole, e podridões (\%), foram avaliadas as aparentes podridões na casca dos frutos que sejam perceptíveis ao olho nu, sendo os resultados expressos em percentagem.

$\mathrm{O}$ delineamento experimental foi inteiramente ao acaso, com esquema fatorial de $3 \times 7$ (tempo $\mathrm{x}$ temperatura). Foram utilizadas 4 repetições, sendo cada uma composta por 9 frutos (aprox. $4 \mathrm{~kg}$ de produto), acondicionada em caixas de papelão.

Os frutos apresentavam as seguintes características antes de aplicarem-se os diferentes tratamentos: $\mathrm{SST}=6,5^{\circ} \mathrm{Brix} ; \mathrm{AT}=0,9(\%)$; índice de coloração do pericarpo $=2,8$; índice de coloração da polpa $=2,6$; firmeza manual $=0,0$, e podridões $=$ $0,0 \%$.

Os resultados obtidos foram analisados estatisticamente pelo programa SAS, sendo submetidos à análise de variância pelo teste $\mathrm{F}$, e teste de comparação de médias, pelo teste de Tukey, a $5 \%$ de probabilidade.

\section{RESULTADOS E DISCUSSÃO}

\section{Teor de sólidos solúveis totais (SST)}

Houve grande variação nos teores de SST durante o armazenamento, para todos os tratamentos testados (Figura 1).

Imediatamente após a aplicação dos tratamentos (dia 0), o tratamento sem aplicação de etileno (T1) apresentou valores médios de SST significativamente inferiores aos valores dos tratamentos com aplicação de etileno (T2 a T7) (Figura 1).

O etileno apresenta controle negativo sobre os seus receptores localizados na membrana celular, significando que, na ausência do etileno, os receptores enviam um sinal para dentro da célula com certas vias metabólicas preestabelecidas, no momento em que acontece a ligação do etileno ao seu sítio receptor, e este sinal é desligado, dando 
lugar a uma sequência de eventos a nível celular, que culminam com a síntese de novas proteínas, que vão acelerar a senescência.

Após a aplicação de etileno, os precursores destes sítios receptores, na mangueira, apresentam um aumento (ISH-SHALOM, 2011), desencadeando, entre outras coisas, maior metabolismo dos carboidratos no processo de amadurecimento das mangas, como o encontrado neste experimento.

\section{Acidez titulável (AT)}

Diferenças significativas foram observadas nos teores de acidez titulável dos frutos, nos diferentes tratamentos, no decorrer do armazenamento, sendo que, em média, houve diminuição de $460 \%$ entre os valores de acidez após os tratamentos (dia 0) e ao final do experimento (dia 14) (Figura 1).

No $7^{\circ}$ dia de avaliação, o tratamento sem etileno (T1) foi significativamente superior aos demais tratamentos (T2 a T7), sendo que, nestes últimos tratamentos, havia sido aplicado etileno exógeno sob diferentes temperaturas (Figura 1).

\section{Índice de coloração do pericarpo}

A mudança de cor que se observa durante a maturação da maioria das frutas é a transformação mais óbvia e, na maioria das vezes, o principal critério utilizado pelo produtor para julgar a sua maturação. É também o atributo de qualidade mais atrativo para o consumidor. As modificações na coloração ocorrem, normalmente, devido à destruição da clorofila e à síntese de novos pigmentos.

Todos os tratamentos mudaram de cor, de uma tonalidade verde para uma laranja avermelhada (Figura 2).

\section{Índice de coloracão da polpa}

A cor da polpa variou de branco-amarela para amarelo-laranja para todos os tratamentos (Figura 2). O T5 (aplicação de 25 ppm de etileno, por dois dias a $20^{\circ} \mathrm{C}$ ) apresentou o maior índice de coloração da polpa ao final do experimento (Figura 2).

A temperatura e o tempo de aplicação de etileno exógeno, com o objetivo de uniformizar o amadurecimento da manga, vai depender da variedade a ser tratada e das condições edafoclimáticas onde a mangueira está sendo produzida, isto é, confirmado pelos resultados obtidos por O'Hare (1995), que obteve o melhor índice de coloração da polpa quando as mangas do $\mathrm{cv}$. Kensington foram amadurecidas com etileno a $22^{\circ} \mathrm{C}$, temperatura diferente da obtida no presente experimento, como sendo a melhor para a aplicação de etileno, que foi de $20^{\circ} \mathrm{C}$.

\section{Firmeza manual do fruto}

A firmeza é uma das características da textura e corresponde ao grau de resistência dos tecidos vegetais à compressão. É relacionada com a composição e com o grau de solubilização das pectinas das paredes celulares e da lamela média (CHITARRA; CHITARRA, 2006).

Houve uma perda de firmeza em todos os tratamentos ao longo do armazenamento, sendo esta perda significativamente superior, nos frutos tratados com etileno (T2 a T7) em comparação com os não tratados (T1) (Figura 3).

Resultados similares de decréscimos de perda de firmeza ao longo do armazenamento também foram obtidos por Braz et al. (2008) em mangas das cultivares Tommy Atkins e Ubá, tratadas com etileno.

\section{Podridões}

As podridões nos frutos de todos os tratamentos foi zero, e após os frutos saírem dos tratamentos (dia 0 ), estas podridões foram menores que $10 \%$ somente nos frutos dos tratamentos $\mathrm{T} 3$, T4, T5 e T7, no $7^{\circ}$ dia de avaliação, sendo $10 \%$ de frutos com presença de podridões a olho nu o limiar utilizado na Austrália para aceitar ou não os frutos para comercialização interna. Este limite foi utilizado no presente projeto, no $14^{\circ}$ dia de avaliação, e todos os tratamentos apresentaram podridões superiores a $10 \%$, porém o T5 (aplicação de 25 ppm de etileno, por dois dias a $20^{\circ} \mathrm{C}$ ) foi o tratamento que se apresentou significativamente inferior aos demais (Figura 3).

Como foi observado até o momento, o tratamento 5, ou seja, a aplicação de etileno, por dois dias a $20^{\circ} \mathrm{C}$, foi aquele no qual se obtiveram os frutos com melhor coloração de polpa e também foram os que apresentaram as menores podridões ao longo do armazenamento. 


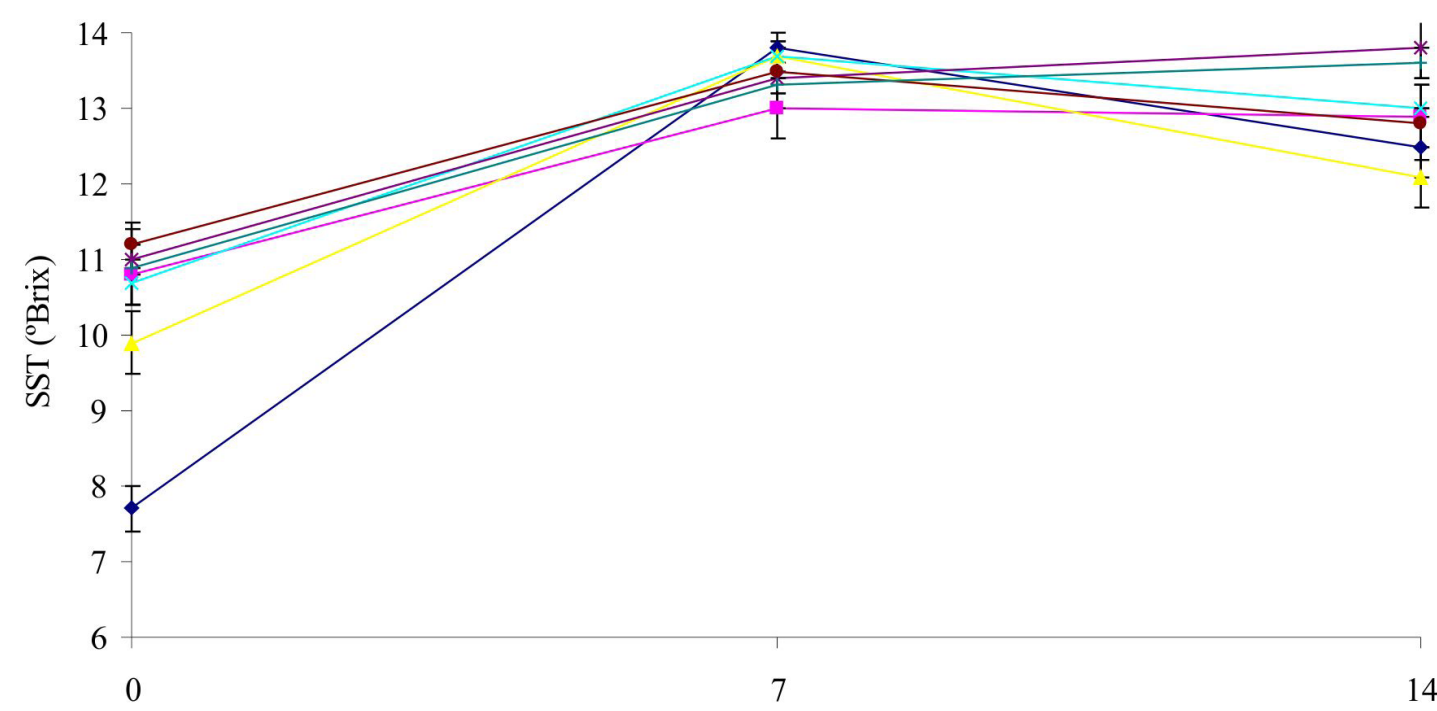

dias a $20^{\circ} \mathrm{C}$ ou ambiente após tratamentos

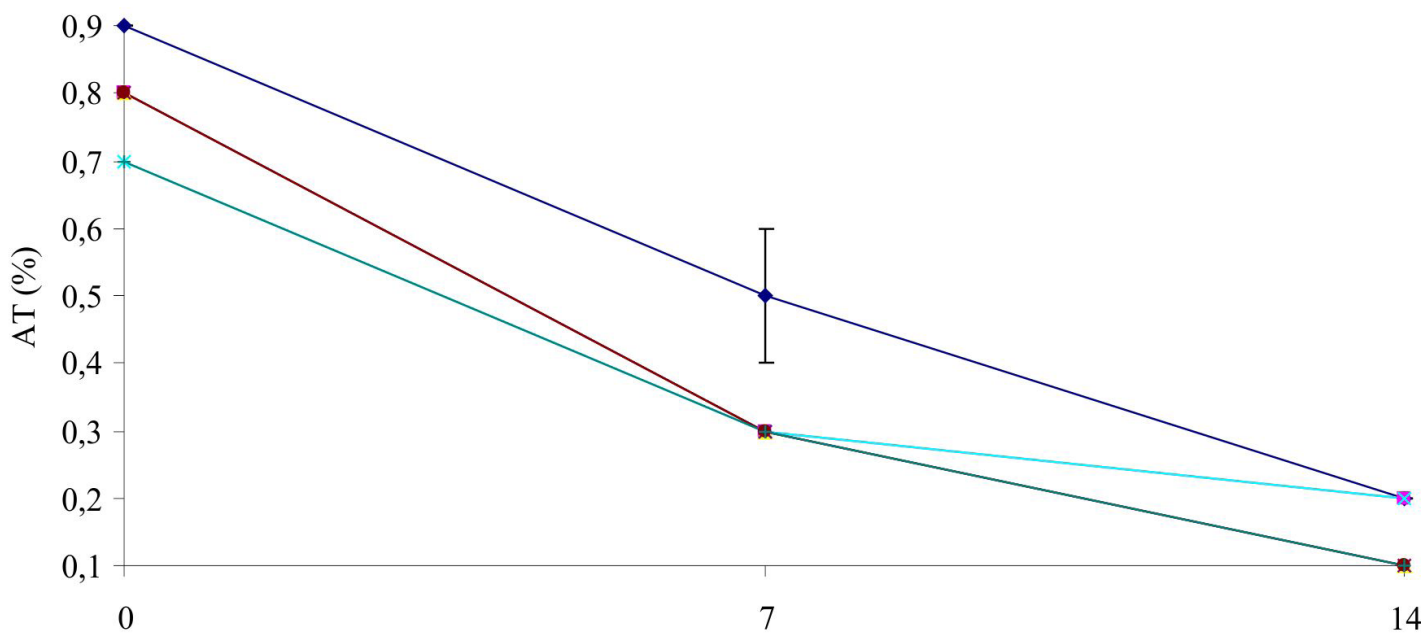

días a $20^{\circ} \mathrm{C}$ ou ambiente após tratamentos

$$
\rightarrow-\mathrm{T} 1 \rightarrow-\mathrm{T} 2 \rightarrow \mathrm{T} 3 \rightarrow \mathrm{T} 4 \rightarrow \mathrm{T} 5 \rightarrow \mathrm{T} 6 \rightarrow \mathrm{T} 7
$$

FIGURA 1 - Sólidos solúveis totais-SST ('Brix) e acidez total-AT (\%) de manga 'Tommy Atkins' tratada ou não com etileno exógeno ( $25 \mathrm{ppm}$ de etileno por 2 dias) sob diferentes temperaturas de aplicação do etileno $(\mathrm{T} 1=$ ambiente sem etileno; $\mathrm{T} 2=$ ambiente com etileno; $\mathrm{T} 3=$ etileno a $16^{\circ} \mathrm{C}$; T4 = etileno a $18^{\circ} \mathrm{C}$; T5 = etileno a $20^{\circ} \mathrm{C}$; T6 = etileno a $22^{\circ} \mathrm{C}$ e $\mathrm{T} 7=$ etileno a $24^{\circ} \mathrm{C}$ ) e armazenadas a $20^{\circ} \mathrm{C}$ e $90 \%$ UR (T3 a T7) ou ambiente $\left(24^{\circ} \mathrm{C}\right.$ e $65 \% \mathrm{UR}-\mathrm{T} 1$ e T2). Barras verticais representam o erro padrão da média $(n=4)$. 


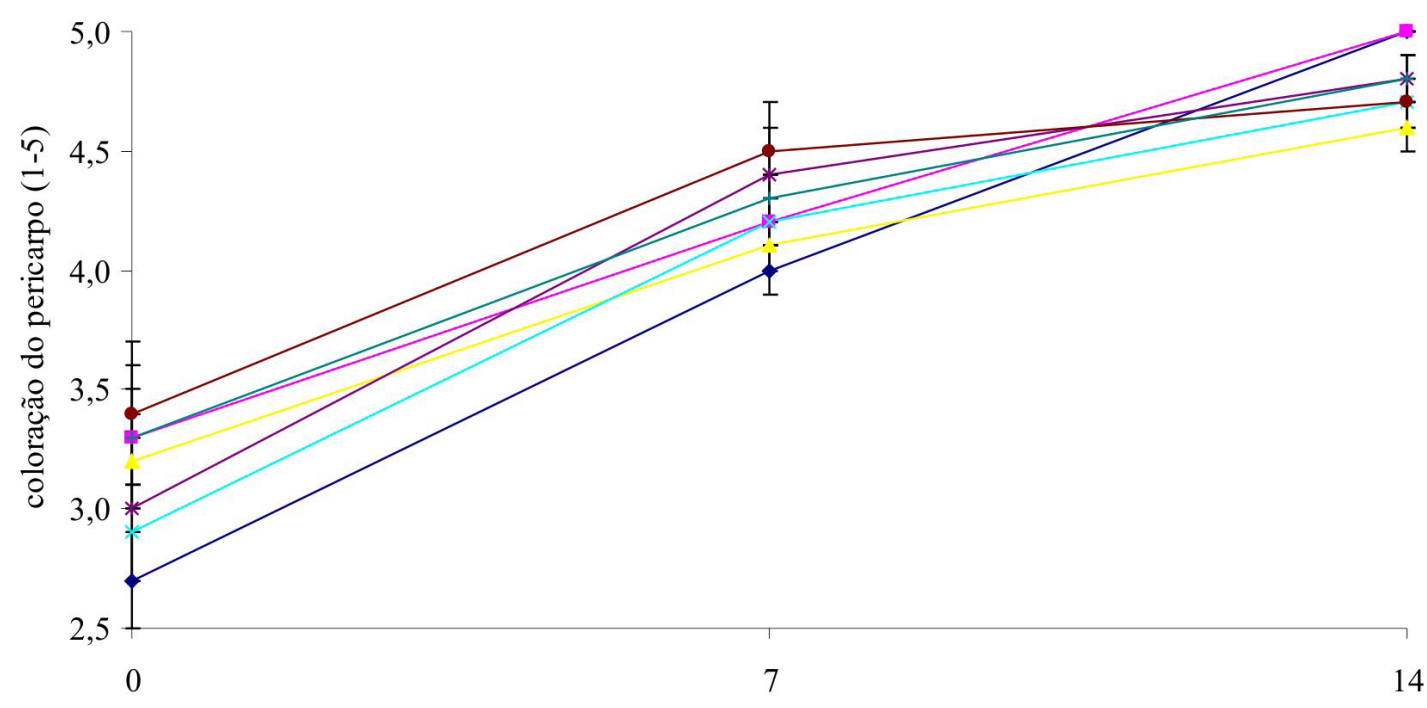

dias a $20^{\circ} \mathrm{C}$ ou ambiente após tratamentos

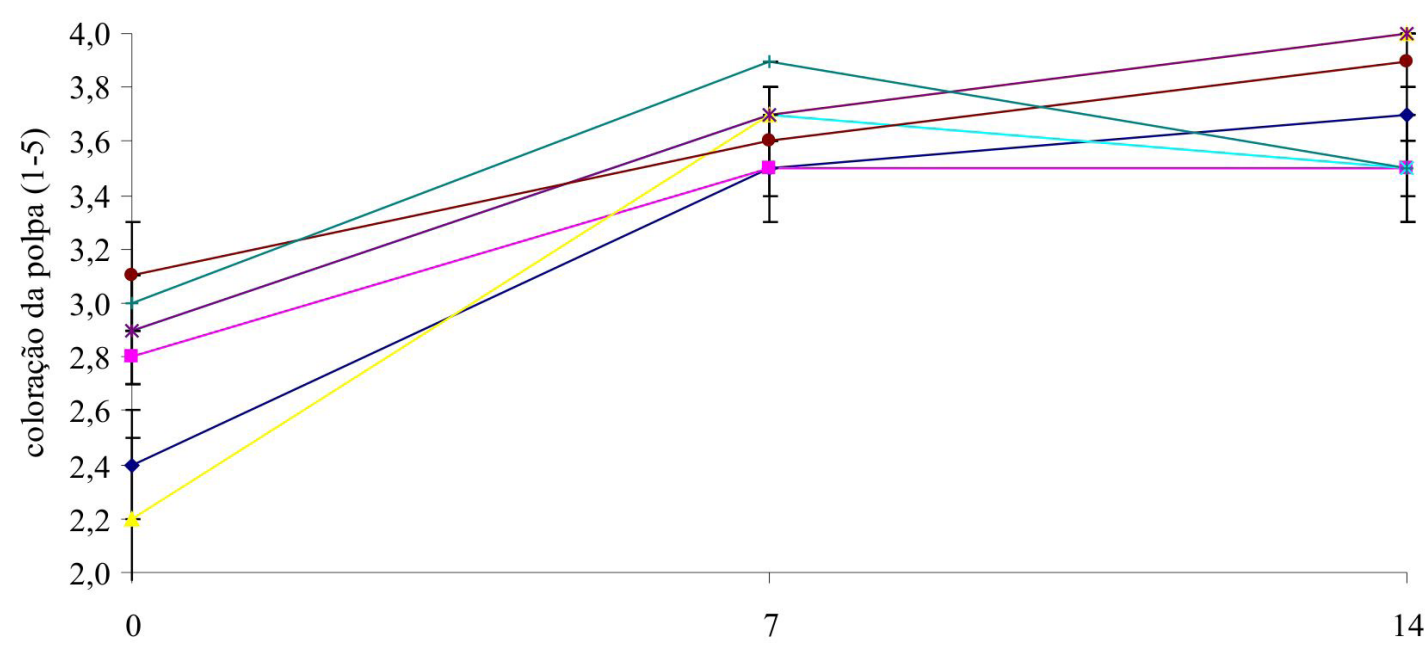

dias a $20^{\circ} \mathrm{C}$ ou ambiente após tratamentos

$$
\rightarrow \mathrm{T} 1 \rightarrow-\mathrm{T} 2 \rightarrow \mathrm{T} 3 \rightarrow \mathrm{T} 4 \rightarrow \mathrm{T} 5 \rightarrow \mathrm{T} 6+\mathrm{T} 7
$$

FIGURA 2 - Índice de coloração do pericarpo $(1=$ totalmente verde; 2 = mais verde que vermelha; 3 $=$ iguais proporções de verde e vermelha; $4=$ mais vermelha que verde e $5=$ totalmente vermelha) e índice de coloração da polpa ( 1 = totalmente branca; 2 = branco-amarelada; 3 = amarela; 4 = amarelo-alaranjado e 5 = totalmente laranja) de manga 'Tommy Atkins' tratada ou não com etileno exógeno ( 25 ppm de etileno por 2 dias) sob diferentes temperaturas de aplicação do etileno $(\mathrm{T} 1=$ ambiente sem etileno; $\mathrm{T} 2$ = ambiente com etileno; $\mathrm{T} 3$ = etileno a $16^{\circ} \mathrm{C}$; T4 = etileno a $18^{\circ} \mathrm{C}$; T5 = etileno a $20^{\circ} \mathrm{C}$; T6 = etileno a $22^{\circ} \mathrm{C}$ e $\mathrm{T} 7=$ etileno a $24^{\circ} \mathrm{C}$ ) e armazenadas a $20^{\circ} \mathrm{C}$ e $90 \%$ UR (T3 a T7) ou ambiente $\left(24^{\circ} \mathrm{C}\right.$ e $65 \%$ UR - T1 e T2). Barras verticais representam o erro padrão da média $(n=4)$. 


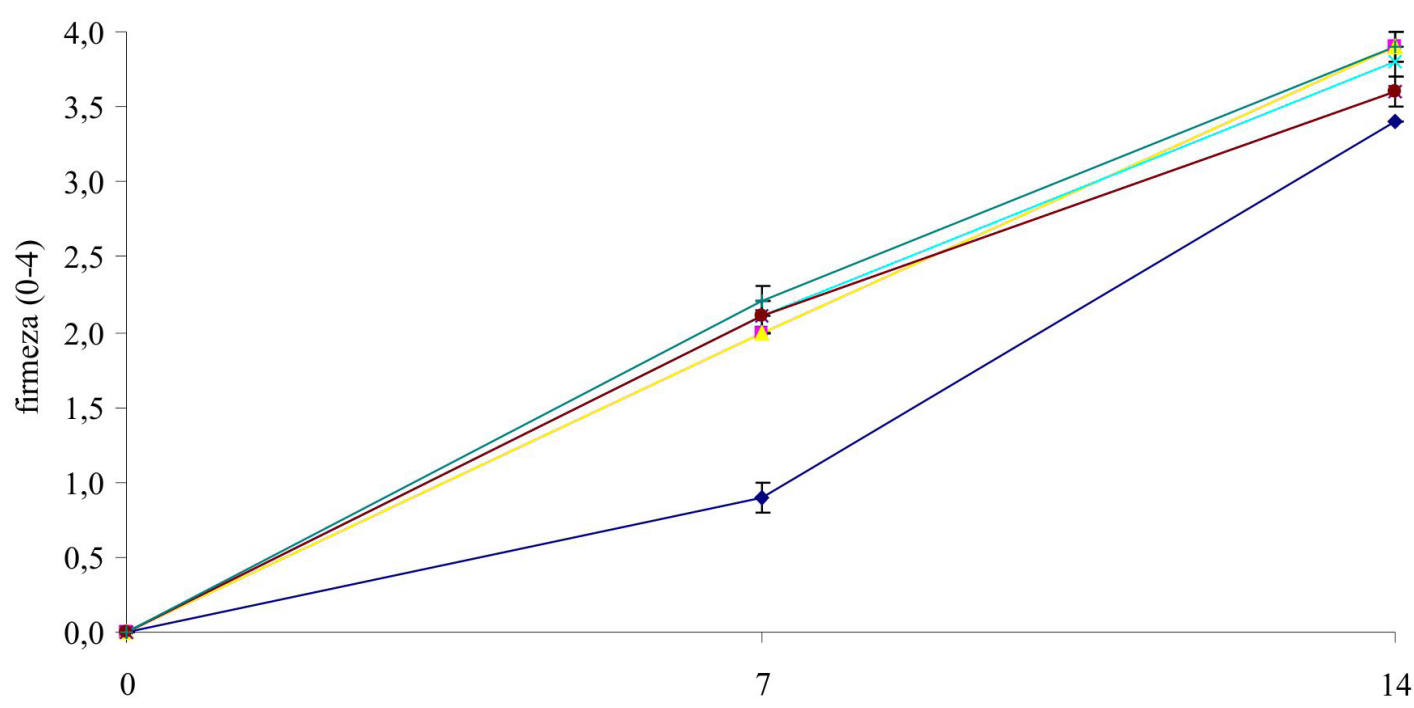

dias a $20^{\circ} \mathrm{C}$ ou ambiente após tratamentos

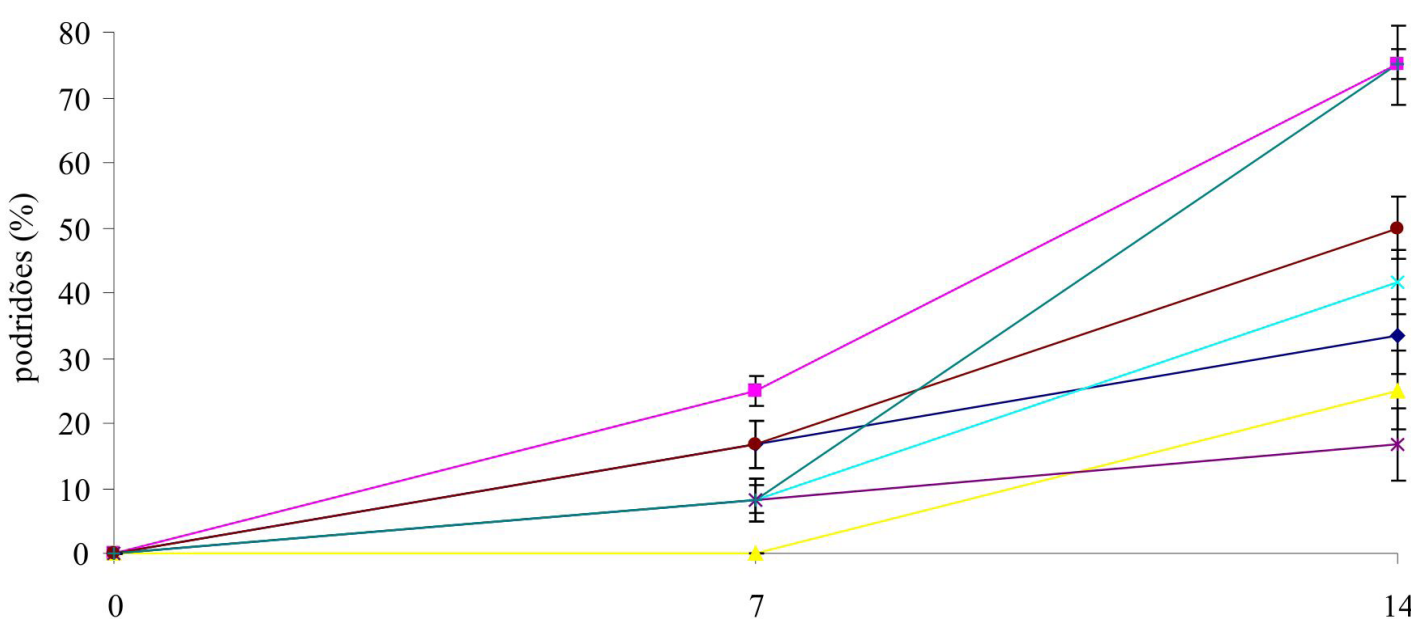

dias a $20^{\circ} \mathrm{C}$ ou ambiente após tratamentos

$\rightarrow \mathrm{T} 1 \rightarrow-\mathrm{T} 2 \rightarrow \mathrm{T} 3 \rightarrow \mathrm{T} 4 \rightarrow \mathrm{T} 5 \rightarrow \mathrm{T} 6 \rightarrow \mathrm{T} 7$

FIGURA 3 - Firmeza manual $(0,0=$ duro (firme); 1 = mais ou menos duro; $2=$ pouco mole; $3=$ mole e $4=$ muito mole) e podridões (\%) de manga 'Tommy Atkins' tratada ou não com etileno exógeno (25 ppm de etileno por 2 dias) sob diferentes temperaturas de aplicação do etileno (T1 = ambiente sem etileno; $\mathrm{T} 2=$ ambiente com etileno; $\mathrm{T} 3=$ etileno a $16^{\circ} \mathrm{C} ; \mathrm{T} 4=$ etileno a $18^{\circ} \mathrm{C}$; $\mathrm{T} 5=$ etileno a $20^{\circ} \mathrm{C} ; \mathrm{T} 6=$ etileno a $22^{\circ} \mathrm{C}$ e $\mathrm{T} 7=$ etileno a $24^{\circ} \mathrm{C}$ ) e armazenadas a $20^{\circ} \mathrm{C}$ e $90 \%$ UR (T3 a T7) ou ambiente $\left(24^{\circ} \mathrm{C}\right.$ e $65 \% \mathrm{UR}-\mathrm{T} 1$ e T2). Barras verticais representam o erro padrão da média $(n=4)$. 


\section{CONCLUSÃO}

A temperatura de $20^{\circ} \mathrm{C}$ é a recomendada para a aplicação de etileno exógeno no amadurecimento de manga 'Tommy Atkins'.

\section{AGRADECIMENTO}

Os autores agradecem à Fundação de Amparo à Pesquisa do Estado de São Paulo (FAPESP), pelo suporte financeiro fornecido a este trabalho (Proc. $n^{\circ}$ 2008/09888-6).

\section{REFERÊNCIAS}

AGRIANUAL 2007. Anuário da agricultura brasileira. São Paulo: FNP Consultoria \& Comércio, 2007. p.378-386.

AGRIANUAL 2008. Anuário da agricultura brasileira. São Paulo: FNP Consultoria \& Comércio, 2008. p.376-382.

BLEINROTH, E.W. Colheita, embalagem, maturação e conservação da manga. In: SIMPÓSIO BRASILEIRO SOBRE A CULTURA DA MANGUEIRA, 1., 1980, Jaboticabal. Anais... Jaboticabal: UNESP, 1980. p. 149-163.

BRAZ, V.B.; NUNES, E.S.; VIEIRA, G.; RIBEIRO, J.I.; BERTINI, L.A.; COUTO, F.A. Indução do amadurecimento de mangas cv. Tommy Atkins e cv. Ubá pela aplicação de ethepon pós-colheita. Bragantia, Campinas, v.67, n.1, p.225-232, 2008.

CHITARRA, M.J.; CHITARRA, A.B. Pós-colheita de frutos e hortaliças: glossário. Lavras: Editora UFLA, 2006. 256p.

COHEN, G.; AGUIRRE, C.; VERA, B.F. Cultivos subtropicales palta y mango: producción y analisis de mercado. Buenos Aires: INTA, 2001. 38p.

FUCHS, Y.; ZAUBERMAN, G.; YANKO, U.; HOMSKY, S. Ripening of mango fruits with ethylene. Tropical Science, Whurr, v.17, p.211-216, 1975.
GALAN SAÚCO, V. El cultivo del mango. Madrid: Ediciones Mundi Prensa, 1999.

ISH-SHALOM, M.; DAHAN, Y.; IRIHIMOVITCH. Cloning and molecular characterization of an ethylene receptor gene, MiERS1, expressed during mango fruitlet abscission and fruit ripening. Plant Physiology and Biochemistry, Wagenigen, 2001. In Press.

MARQUES, J.R.; HOFMAN, P.; NISSEN, R. Mango postharvest manual. Queensland: QDPI\&F, 2007. 53p.

MATOS, A.P. Manga Produção: aspectos técnicos. Brasília: Embrapa, 2000. 63p.

MEDLICOTT, A. P.; REYNOLDS, S.B.; THOMPSON, A. K. Effects of temperature on the ripening of mango fruit (Mangifera indica L.) var. Tommy Atkins. Journal of the Science of Food and Agriculture, London, v.37, n.5, p.469-474, 1986.

O'HARE, T.J. Effect of ripening temperature on quality and compositional changes of mango (Mangifera indica L.) cv. Kensington. Australian Journal of Experimental Agriculture, Nambour, v.35, p.259-263, 1995.

RIBEIRO, S.M.R.; BARBOSA, L.C.A.; QUEIROZ, J.H.; KNODLER, M.; SCHIEBER, A. Phenolic compounds and antioxidant capacity of Brazilian mango (Mangifera indica L.) varieties. Food Chemistry, London, v.110, p.620-626, 2008.

ROZANE, D.E.; DAREZZO, R.J.; AGUIAR, R.L.; AGUILERA, G.H.A.; ZAMBOLIM,L. Manga: produção integrada, industrialização e comercialização.Viçosa: UFV, 2004. 604p.

SÃO JOSÉ, A. R. Considerações gerais sobre a mangicultura. In: SÃO JOSÉ, A. R. et al. Manga: tecnologia de produção e mercado. Vitória da Conquista: DFZ/UESB, 1996. p. 1-6.

SIMÃO, S. Tratado de fruticultura. Piracicaba: FEALQ, 1998. 760p. 